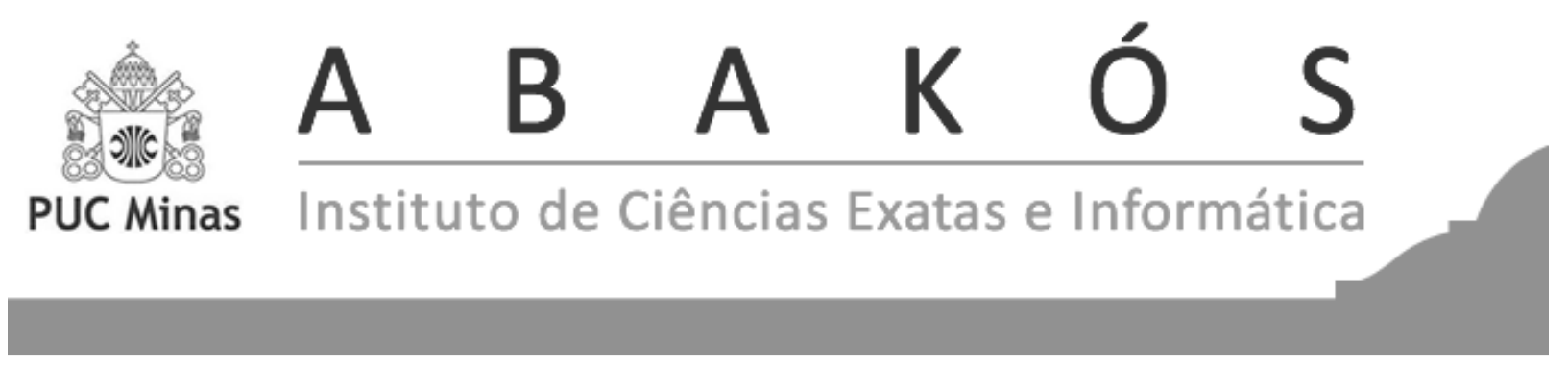

\title{
Análise das Estratégias Utilizadas por Docentes do Ensino Fundamental para Resolver Tarefa Exploratório-Investigativa no Ensino da Pré-álgebra*
}

Analysis of the Strategies Used by Elementary School Teachers to Solve Investigative Exploratory Task to Teach Pre-Algebra

\author{
Márcia Jussara Hepp Rehfeldt ${ }^{1}$ \\ Marli Teresinha Quartieri ${ }^{2}$ \\ Ieda Maria Giongo ${ }^{3}$ \\ Camila Baseggio Gräff ${ }^{4}$ \\ Taylane Katz ${ }^{5}$ \\ Camila Troian ${ }^{6}$
}

\begin{abstract}
Resumo
O presente trabalho é oriundo de um grupo de pesquisa integrado por professores, mestrandos e bolsistas de graduação, e tem como objetivo relatar o desenvolvimento e os resultados emergentes de uma atividade investigativa elaborada pelo grupo em questão. Os dados aqui apresentados procedem de uma formação continuada de professores, realizada em uma cidade do Vale do Taquari, no segundo semestre do ano de 2017, em que o grupo de pesquisa, em conjunto com a Secretaria Municipal, propôs a realização de atividades de cunho exploratório-investigativa. O objetivo era integrar setenta professores que atuavam nos Anos Iniciais do Ensino Fundamental de modo que os envolvidos participassem de forma ativa e se inteirassem de novos métodos de ensino. Salienta-se que a coleta de dados se embasou nas transcrições dos áudios gravados durante a prática, além de fotos e anotações contidas nos diários de campo dos pesquisadores. Os resultados analisados apontam
\end{abstract}

\footnotetext{
* Submetido em 04/02/2019 - Aceito em 06/09/2019

${ }^{1}$ Doutora. Docente do Mestrado profissional em ensino de Ciências Exatas e do Mestrado em ensino pela Univates, Brasil-mrehfeld@univates.br

${ }^{2}$ Doutora. Docente do Mestrado profissional em ensino de Ciências Exatas e do Mestrado em ensino pela Univates, Brasil-mtquartieri@univates.br

${ }^{3}$ Doutora. Docente do Mestrado profissional em ensino de Ciências Exatas e do Mestrado em ensino pela Univates, Brasil-igiongo@univates.br

${ }^{4}$ Estudante de Pedagogia. Bolsista Voluntária, Brasil- camila.graff@ universo.univates.br

${ }^{5}$ Estudante de Arquitetura, Brasil- taylane.katz@universo.univates.br

${ }^{6}$ Estudante de Odontologia, Brasil-camila.troian@universo.univates.br
} 
a emergência de duas conjecturas diferentes para resolução da tarefa aplicada. Ademais, observou-se a importância do material manipulativo para alcançar o objetivo de encontrar conjecturas corretas para a tarefa.

Palavras-chave: Estratégias. Pré-álgebra. Anos Iniciais. 


\begin{abstract}
This work reports the development and the emerging results of an investigative activity prepared by a research group composed of professors, master's students and scholarships. The data presented here come from a continuous teacher training program, held in a town of the Taquari Valley, in the second semester of 2017. The research group, in conjunction with the city government, proposed investigative exploratory activities, intending to integrate seventy teachers, who worked in the early years of elementary school, so that they could participate actively and learn about new methods of teaching. The data collection was based on the transcriptions of the audios recorded during the practice, as well as photos and annotations contained in the researchers' field diaries. The analysis of the results indicate the emergence of two different conjectures to solve the assigned task. It was observed the importance of manipulative material to achieve the goal of finding the correct conjectures for the task.
\end{abstract}

Keywords: Strategies. Pre-Algebra. Early Years. 


\section{INTRODUÇÃO}

Sabe-se que, na formação inicial do professor, devem ser considerados, principalmente, conhecimentos que o habilitem a exercer a docência na complexidade que a profissão exige. Contudo, o tempo destinado para tal tem sido insuficiente para formá-lo em sua plenitude, sendo necessárias a experiência e a vivência. Esses são alguns motivos pelos quais se devem oportunizar momentos de formação continuada aos que ministram aulas na Escola Básica, buscando torná-los docentes pesquisadores reflexivos em relação às suas práticas. Nesse sentido, de acordo com Demo (2007), encontros de pós-formação proporcionam momentos de análise acerca da prática pedagógica, promovendo mudança de postura, em que o aluno não seja objeto, mas o sujeito do processo.

Pensando nisso, um grupo de pesquisa, denominado Práticas, Ensino e Currículos (PEC), vinculado à Universidade do Vale do Taquari - Univates, pesquisou, formulou e refinou atividades contemplando, à luz da Investigação Matemática, o estudo da Álgebra por meio de materiais manipuláveis. Tais práticas discutidas no grupo PEC são oriundas de encontros semanais que perduraram a cerca de seis meses. Ressalva-se que tal grupo, semanalmente, encontrava-se com o intuito de confeccionar, refinar e planejar as tarefas exploratórias, além de discutir métodos e meios de intervenção.

Além disso, tais atividades pertencem particularmente à pesquisa intitulada "Ensinoaprendizagem-avaliação em Matemática nos Anos Iniciais do Ensino Fundamental: atividades exploratório-investigativas e formação docente", vinculada à referida Universidade, obtendo o aval da Secretaria de Educação do Município, em que se ofertaram momentos de reflexão a docentes durante encontros de formação-continuada. Também cabe salientar que a citada pesquisa é financiada pelo Conselho Nacional de Desenvolvimento Científico e Tecnológico (CNPq). Logo, com base nos dados iniciais deste artigo, tem-se por objetivo relatar o desenvolvimento e os resultados emergentes de uma atividade investigativa elaborada pelo grupo em questão e explorada com professoras dos Anos Iniciais da Escola Básica.

\section{REFERENCIAL TEÓRICO}

A Investigação Matemática é uma tendência que permite aos alunos descobrirem e formularem suas hipóteses em relação às atividades propostas pelo professor. Ponte et al. (2003, p.23) veem o uso das investigações matemáticas como "atividades de ensino-aprendizagem" que buscam o "espírito da atividade matemática genuína". Segundo os autores, durante as tarefas investigativas, o discente formula conjecturas, testa-as e realiza refinações.

Ademais, pode apresentar os resultados obtidos durante a realização dessa tarefa e discuti-la, em grupo, com os colegas. Nesse momento, busca-se no professor um papel de pesquisador e de instigador. Entende-se como "professor pesquisador" aquele que explicita as inquietudes que emergem da sua prática e as toma como problema de pesquisa, procurando 
soluções fundamentadas com o objetivo de propor e empregar mudanças concretas na sala de aula e/ou na instituição (BÚRIGO et al., 2012).

Para isso, "o pensamento lógico-matemático é um dos atributos da construção mental que pode ser construído mediante as orientações do professor com objetos desafiadores, sobre quais os alunos possam pensar e estabelecer relações" (GHELLI K. G. M; SANTOS, 2015). Essas construções precisam ser instigadas e estimuladas com atividades significativas para o discente.

Nesse sentido, os materiais manipuláveis se tornam cada vez mais procurados pelos docentes, já que são formas de o aluno ver, sentir e tocar no objeto com o propósito de entender o que é solicitado durante uma prática. Sendo assim, a "utilização de materiais manipuláveis pode fazer com que a matemática se torne viva e que as ideias abstratas tenham significado através de experiências com objetos reais" (SANTOS; SIQUEIRA, 2017, p.610). Em outras palavras, o objetivo dos materiais manipuláveis é "provocar situações em que os interesses possam emergir e o aluno possa atuar" (VASCONCELLOS, 1999, p.83). Porém, na tendência Investigação Matemática, há a possibilidade de o ensino se tornar um desafio para o professor no momento em que ele utilizar esses materiais, já que é preciso tempo para aprender a manuseálos, bem como refletir sobre possíveis conjecturas que venham a surgir no momento em que forem contatados pelos alunos.

Ademais, seu emprego exige planejamento e estudo do docente, pois dúvidas sobre as diferentes conjecturas podem emergir durante a prática pedagógica. Santos e Siqueira (2017, p.610) salientam que "ao utilizar esses materiais o professor deverá ter conhecimento a respeito dos mesmos, podendo assim fazer uma seleção criteriosa, relacionando-os ao conteúdo trabalhado em sala de aula".

Diante desses referenciais e com um conhecimento prévio acerca das dificuldades dos professores de Matemática dos Anos Iniciais, o grupo de pesquisadores selecionou o conteúdo de Álgebra, tema presente na Base Nacional Curricular Comum (BNCC). Segundo o documento, "é imprescindível que algumas dimensões do trabalho com a álgebra estejam presentes nos processos de ensino e aprendizagem desde o Ensino Fundamental" (BRASIL, 2017, p.266). Ainda está expresso que algumas ideias de trabalho deverão contemplar "generalização de padrões e propriedades da igualdade. No entanto, nessa fase, não se propõe o uso de letras para expressar regularidades, por mais simples que sejam". (BRASIL, 2017, p.266). Corroborando essas ideias, (GROENWALD, 2014, p.2) sustenta que

A álgebra faz parte do processo de Educação Matemática vivenciado pelos estudantes desde as séries iniciais do Ensino Fundamental, embora, nos primeiros anos de escolarização não seja de modo formalizado. Já nos primeiros anos do Ensino Fundamental, quando o aluno aprende a calcular o valor desconhecido, em problemas de Matemática, mesmo sem atribuir a esse um valor ou símbolo que o represente, já está sendo introduzido o pensamento algébrico.

Para Blanton e Kaput (2005, p.413), o pensamento algébrico se refere ao processo pelo qual os alunos "generalizam ideias matemáticas a partir de um conjunto de casos particulares, 
estabelecem essas generalizações através de discurso argumentativo, e expressam-nas de formas progressivamente mais formais e adequadas à sua idade". Por sua vez, Kieran (2004, p.149) afirma que

o pensamento algébrico nos primeiros anos de escolaridade envolve o desenvolvimento de maneiras de pensar em atividades em que o símbolo-letra da Álgebra pode ser usado como ferramenta, que não é exclusiva da Álgebra, e que podem ser realizadas sem usar qualquer símbolo-letra da Álgebra, tais como, analisar relações entre quantidades, perceber estruturas, estudar a mudança, generalizar, resolver problemas, modelar, justificar e prever.

De forma similar, Almeida (2016) acredita que o pensamento algébrico se caracteriza como forma de estabelecer relações e, a partir das constatações, construir significados. Finalizam-se esses referenciais com a premissa da BNCC (Base Nacional Comum Curricular), na qual se lê que a Álgebra

tem como finalidade o desenvolvimento de um tipo especial de pensamento pensamento algébrico - que é essencial para utilizar modelos matemáticos na compreensão, representação e análise de relações quantitativas de grandezas e, também, de situações e estruturas matemáticas, fazendo uso de letras e outros símbolos (BRASIL, 2017, p.268).

Logo, os autores deste artigo, embasados nos pesquisadores discutidos nesta seção, ponderam que se pode iniciar o pensamento algébrico nos Anos Iniciais, por meio do qual os alunos expressam suas conjecturas oralmente ou ainda por escrito, sem necessariamente usar letras ou símbolos. Entende-se que, dessa forma, o discente estará construindo a sua Pré-Álgebra, essencial à continuidade da aprendizagem da Álgebra propriamente dita.

Assim, a atividade proposta às docentes e aqui apresentada teve como essência promover uma prática que possibilitasse ao aluno chegar a distintas generalizações e entender o que significa cada letra, símbolo ou número de sua generalização. Steele (2001, p.42), defende a ideia de que "nenhuma outra decisão que o professor toma tem um impacto tão grande nas oportunidades de aprendizagem do aluno e na sua percepção acerca do que é a Matemática, como a seleção ou criação de tarefas".

Tomando como princípio algumas ideias supracitadas, nas próximas seções, descrevemse os procedimentos metodológicos, bem como os resultados encontrados na exploração de uma atividade exploratório-investigativa. Essa foi desenvolvida pelos pesquisadores e proposta às docentes que participaram da formação continuada.

\section{PROCEDIMENTOS METODOLÓGICOS}

A metodologia adotada neste estudo pode ser classificada como qualitativa, pois, de acordo com Freitas e Jabbour (2011, p.10), “a principal vantagem da abordagem qualitativa, em 
relação à quantitativa, refere-se à profundidade e à abrangência, ou seja, o 'valor' das evidências que podem ser obtidas e trianguladas por meio de múltiplas fontes". Gibbs (2009, p.17) afirma que "eles [os dados qualitativos] não incluem contagens e medidas, mas sim praticamente qualquer forma de comunicação humana escrita, auditiva ou visual; por comportamento, simbolismos ou artefatos culturais".

Ao analisar esses escritos, percebe-se que, nos estudos realizados, não se buscou somente uma resposta final. De fato, na Investigação Matemática, o mais importante é o caminho para se chegar a uma expressão/conjectura, isto é, às escritas, enunciações e representações dos docentes.

Como dito anteriormente, a atividade discutida neste trabalho está em conformidade com a Investigação Matemática, alicerçada no conteúdo Álgebra para os Anos Iniciais do Ensino Fundamental. Cumpre também lembrar que ela foi planejada pelo grupo PEC, professores da Univates que atuam na área de Matemática (Física, Química, Matemática), mestrandos e doutorandos do programa de educação, bolsistas de Iniciação Científica de diversos Cursos (Odontologia, Gastronomia, Pedagogia, Arquitetura e Urbanismo), todos vinculados à Universidade, além de docentes da Escola Básica e voluntários, que, semanalmente, têm se reunido para discutir a execução do projeto.

Para o desenvolvimento das questões investigativas, teve-se como suporte os estudos de Ponte et al. (2003), que exploram principalmente o uso da Investigação Matemática como metodologia de apoio ao ensino. Seus trabalhos tendem a seguir alguns passos principais, dentre os quais se destaca o trabalho em grupo alicerçado com o uso de materiais manipulativos.

Sarmento (2010, p.3) comenta que o uso de materiais concretos "permite aos alunos experiências físicas à medida que este tem contato direto com os materiais, ora realizando medições, ora descrevendo, ou comparando com outros de mesma natureza". O autor acrescenta que tais materiais possibilitam "experiências lógicas por meio das diferentes formas de representação que possibilitam abstrações empíricas e abstrações reflexivas, podendo evoluir para generalizações mais complexas" (Ibidem). Nessa perspectiva, o material manipulável, aliado à prática investigativa, contribui para que o aluno conceda significados aos objetos manipulados e, por consequência, compreenda o tema em estudo. Em vista disso, ao perceber que o uso de tais ferramentas favorece o ensino e a aprendizagem dos alunos, optou-se por utilizá-los com os docentes que participaram da formação-continuada.

Ressalva-se, ainda, que o planejamento contou com a formulação de atividades no que abrange as questões e os materiais necessários para seu desenvolvimento que o grupo PEC desenvolveu, durante encontros, na Instituição de Ensino Superior local. Em função de as atividades serem classificadas como "abertas", os participantes do PEC testavam as possibilidades de respostas que poderiam surgir durante os encontros, pois se esperava que as docentes participantes do curso encontrassem mais que uma que satisfizesse os objetivos.

Ponte et al. (2003, p.23) apontam que as questões abertas são perceptíveis quando "não está bem definida no início, cabendo a quem investiga um papel fundamental na sua definição. E uma vez que os pontos de partida podem não ser exatamente os mesmos, os de chegada podem 
ser também diferentes". Portanto, ao encontrar mais que uma conjectura para cada atividade ou mesmo pensamentos distintos que chegam à mesma conclusão, mas por caminhos/formas diferentes, podem e/ou são considerados abertos.

Especificamente no que tange à formação continuada em que a atividade aqui descrita foi desenvolvida, cabe esclarecer que ela ocorreu em uma das escolas do Município que possui parceria com a Universidade e o grupo de pesquisa. Nessa instituição, reuniram-se todos os professores dos Anos Iniciais da rede municipal, totalizando setenta profissionais.

Cada encontro durava cerca de duas horas, haja vista que, inicialmente, as professoras integrantes do grupo "Pesquisa, Ensino e Currículos" apresentavam as tarefas propostas. Cumpre destacar que todos ocorreram no segundo semestre de 2017, à noite. Em seguida, visando à realização das questões, o material necessário era entregue às participantes, que as resolviam em pequenos grupos, formados por elas mesmas, geralmente, por escolas. Finda a atividade, iniciava-se a discussão geral. Assim, oportunizava-se a todas exporem, quando possível.

É importante comentar que, para a coleta de dados, as participantes receberam duas folhas: uma contendo a atividade; outra, de almaço, para representarem suas conjecturas, escrevendo seus pensamentos e realizando seus testes quando necessário. Além desse material, em cada grupo, uma bolsista (do grupo PEC) ficava responsável por capturar momentos em que se visualizavam as figuras que formariam as estratégias utilizadas no processo. Ademais, elas deveriam anotar, em seu diário de bordo, aspectos que observavam e julgavam serem relevantes para futuro estudo.

Salienta-se que as professoras participantes formaram sete grupos, contendo, cada um, em média, dez pessoas, pois, na Investigação Matemática, é fundamental esse tipo de trabalho. Nessa perspectiva, Ponte et al. (2003, p.30) preconizam que

A situação de trabalho em grupo potencializa o surgimento de várias alternativas para a exploração da tarefa, o que numa fase inicial pode ser complicado em termos de autogestão do grupo. Muitas vezes, um ou dois alunos tomam a liderança e levam o grupo a centrar-se em certas ideias, facilitando, assim, o trabalho conjunto.

A atividade citada neste artigo permitiu a manipulação de materiais de baixo custo, ou seja, usaram-se tampas de garrafas PET (Poli Tereftalato de Etila), distribuídas em determinada quantidade, bem como a tarefa a ser desenvolvida e suas respectivas instruções. Essas estão impressas na Figura 1. 


\section{Figura 1 - Atividade com tampinhas de garrafa PET}

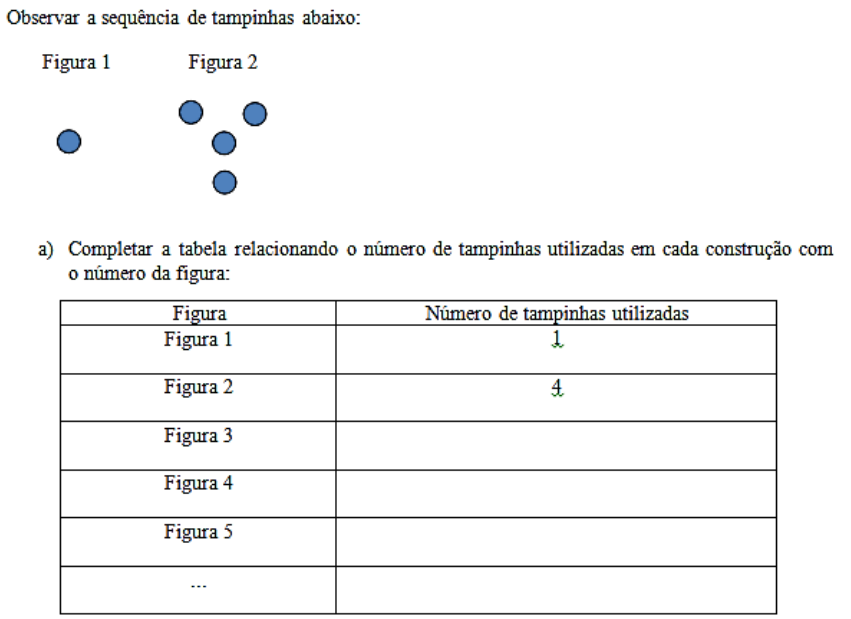

Fonte: Elaborado pelas autoras

Às participantes, solicitou-se que observassem, com atenção, o que estava sendo pedido e transpassassem os desenhos da folha (no caso as tampas) utilizando material concreto para a mesa. Conforme observado pelos ministrantes, elas se sentiam mais seguras com o uso de tal recurso, pois não precisavam usar a borracha quando a conjectura estava incorreta; apenas a refaziam. Ademais, o emprego do concreto favoreceu a contagem, o que leva a pensar que isso também beneficia os alunos dos Anos Iniciais, pois é nessa fase que começa a contagem de números e, com essa atividade, o assunto trabalhado tende a se tornar mais interessante, visto que é visual e manipulável.

Em seguida, após montagem das figuras com as tampinhas, solicitou-se às participantes o preenchimento da tabela ilustrada na letra A da Figura 1. Nela, deveriam descrever a relação que havia entre o número da figura [Figura 1, Figura 2, Figura 3] e a quantidade de tampinhas utilizadas em cada uma delas.

Com o propósito de lhes conceder autonomia, o grupo de pesquisadores delegou às participantes a tarefa de resolver a situação. Assim, elas tiveram a oportunidade de discutir, conjecturar e propor ideias em seus pequenos grupos. Entretanto, foram instigadas pelos formadores em relação à formação das conjecturas e estratégias apresentadas com o intuito de levá-las a expressarem com mais detalhes a resolução que estava sendo proposta. Ainda de acordo com Veiga (1991, p.105):

[...] a interação deverá estar sempre provocando uma influência recíproca entre os participantes do processo de ensino, o que me permite afirmar que os alunos não aprenderão apenas com o professor, mas também através da troca de conhecimentos, sentimentos e emoções dos outros alunos.

Após a discussão em pequenos grupos, com duração aproximada de quarenta e cinco minutos, passou-se à parte final da investigação em que foram compartilhadas as resoluções encontradas. Nesse momento, argumentou-se cada conjectura obtida. Em seguida, apresentam-se os dados coletados na pesquisa, mais especificamente as estratégias e conjecturas encontradas, bem como a discussão acerca delas. 
Para melhor compreensão, os resultados foram apresentados por grupo de acordo com as conjecturas e diálogos que ocorreram entre eles. Ressalta-se que, por uma questão de espaço e proximidade de ideias, relatam-se duas distintas conjecturas: a do Grupo 1 e a do 4. Ainda, em relação às nomenclaturas usadas, D1, D2, D3 e, assim sucessivamente, elas representam as docentes que participaram da formação continuada; enquanto PP1, PP2, os pesquisadores envolvidos.

\section{RESULTADOS EMERGENTES}

A atividade "Sequência com tampinhas de garrafa PET" teve por objetivo investigar as diferentes estratégias utilizadas pelos docentes dos Anos Iniciais ao resolverem a atividade envolvendo o conteúdo de Álgebra. Trata-se de uma metodologia diferenciada da habitual.

Ressalva-se que, neste artigo, discute-se apenas uma atividade que ocorreu no segundo encontro de formação continuada do ano de 2017. Cabe ressaltar que as participantes já estavam habituadas com as ministrantes, o grupo e as atividades. Porém, em encontros anteriores, a insegurança de trabalhar com essa tendência de Investigação Matemática foi visível e, não raro, professoras se retraiam por não obter uma "aprovação/concordância imediata" das docentes do PEC sobre seu pensamento estar ou não correto.

Ademais, nesse dia, após a atividade ser apresentada aos grupos, as participantes observavam e tentavam compreender o que deveriam fazer em cada item solicitado. Salienta-se que não houve interferência dos pesquisadores durante a resolução dos itens da questão proposta.

Schein e Coelho (2006, p.5) sustentam que cabe "ao professor não dar respostas, mas sim promover uma reflexão que se aprofundava quando se dirigia ao aluno com outro questionamento". A Figura 2 ilustra o pensamento adotado pelo Grupo 1.

\section{Figura 2 - Apresentação da conjectura do Grupo 1}

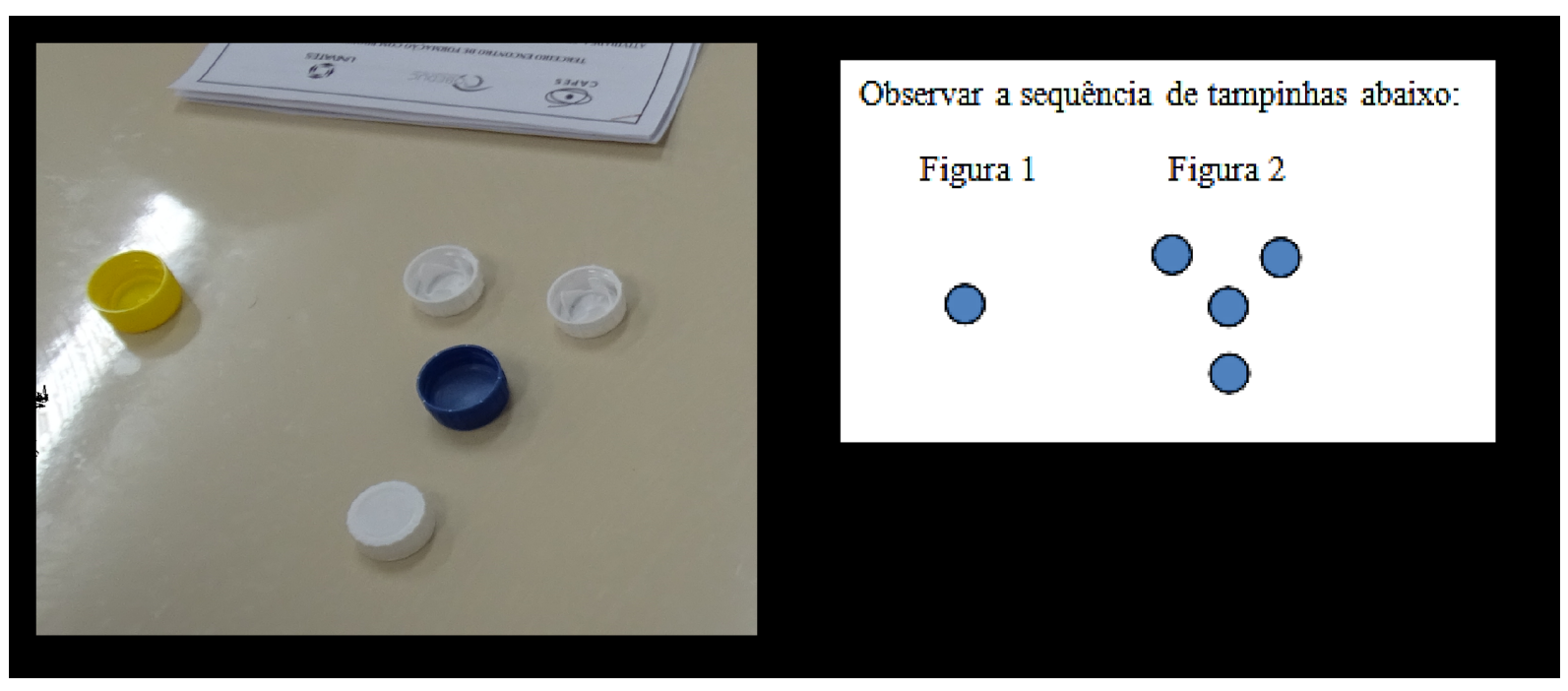

Fonte: Elaborado pelas autoras

Na Figura 2, observa-se que as docentes, inicialmente, reproduziram o que estava no 
papel. Para elas, a primeira figura era a tampinha amarela; na segunda, a primeira tampinha permanecia; porém, dessa vez, ela se encontrava na cor azul. Nela, foram acrescidas três novas tampinhas (ilustradas pela cor branca), uma no lado esquerdo da tampa inicial; uma abaixo e uma no lado direto; formando, assim, uma figura com quatro tampinhas. Essa ideia é confirmada pelo diálogo estabelecido entre as professoras durante a formação, transcrito dos gravadores:

$$
\begin{aligned}
& \text { D1 - A primeira tem uma tampinha [referindo-se à tampinha amarela]. } \\
& \text { PP1 - Essa é a primeira? } \\
& \text { D1 - Sim, e essa, a segunda. } \\
& \text { PP1 - E a terceira? } \\
& \text { D1 - Vai ter três a mais. } \\
& \text { PP1 - Pensem na ideia da primeira figura. E aí, como tu pensou? } \\
& \text { D1 - A sequência tu aumenta três. }
\end{aligned}
$$

Ou seja, da primeira figura, que tinha somente um objeto, para a segunda, aumentaram três tampinhas. Consequentemente, para encontrar alguma generalização, aparecia o número três, pois era o que sempre aumentava em relação à anterior. A Figura 3 ilustra todo o procedimento adotado pelas participantes da formação continuada (ilustrando as quatro primeiras figuras).

\section{Figura 3 - Sequência utilizada pelo Grupo 1 para resolução}

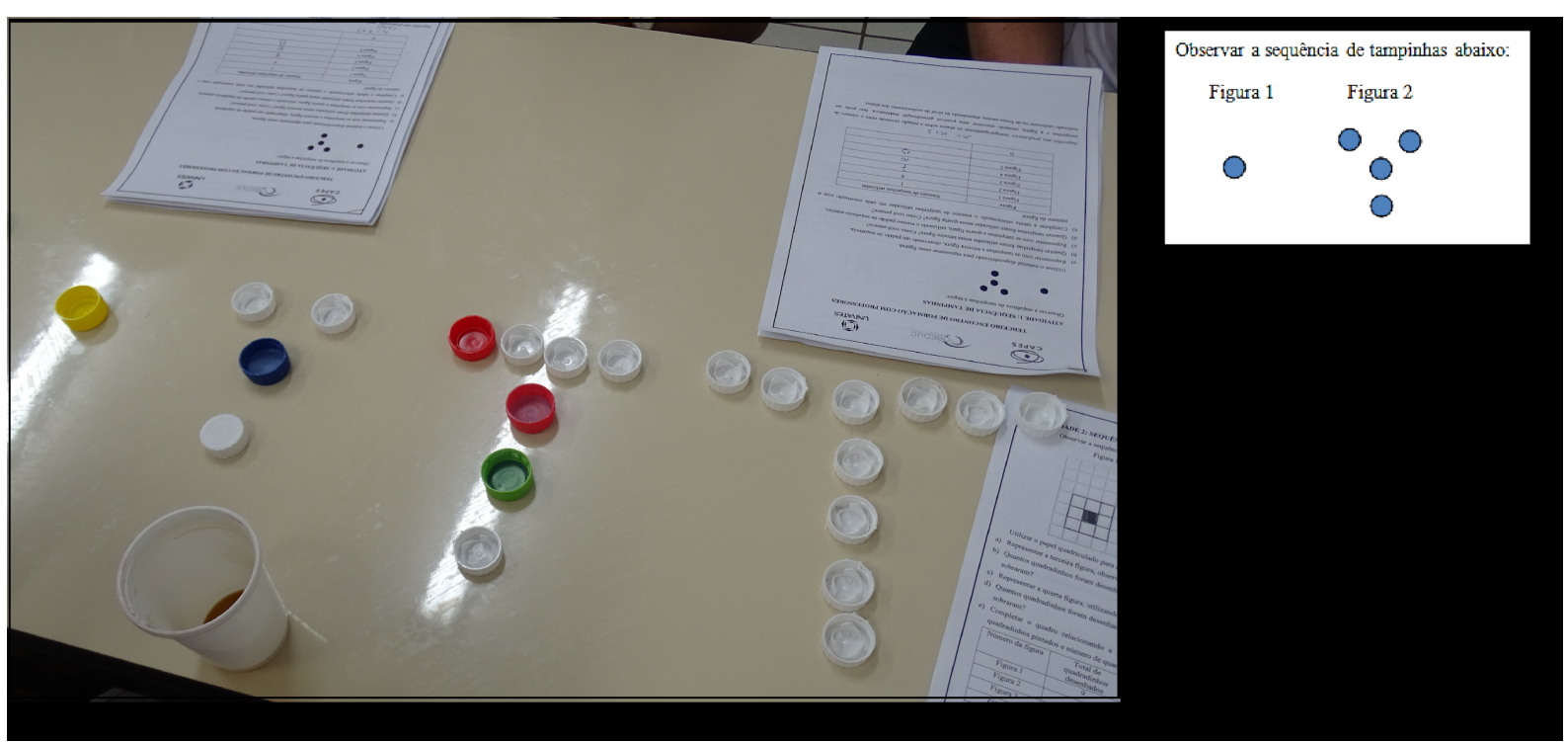

Fonte: Elaborado pelas autoras

Seguindo o procedimento, as participantes continuaram a manter um padrão algébrico, pois pensavam que sempre aumentaria o número de três tampinhas. Logo, por falta de cores distintas, elas utilizaram a verde, uma vermelha e duas brancas para manter a figura original presente na figura dois e acrescentaram três novas tampinhas conforme ilustrado na Figura 4. 


\section{Figura 4 - Continuação da sequência utilizada pelo Grupo 1}

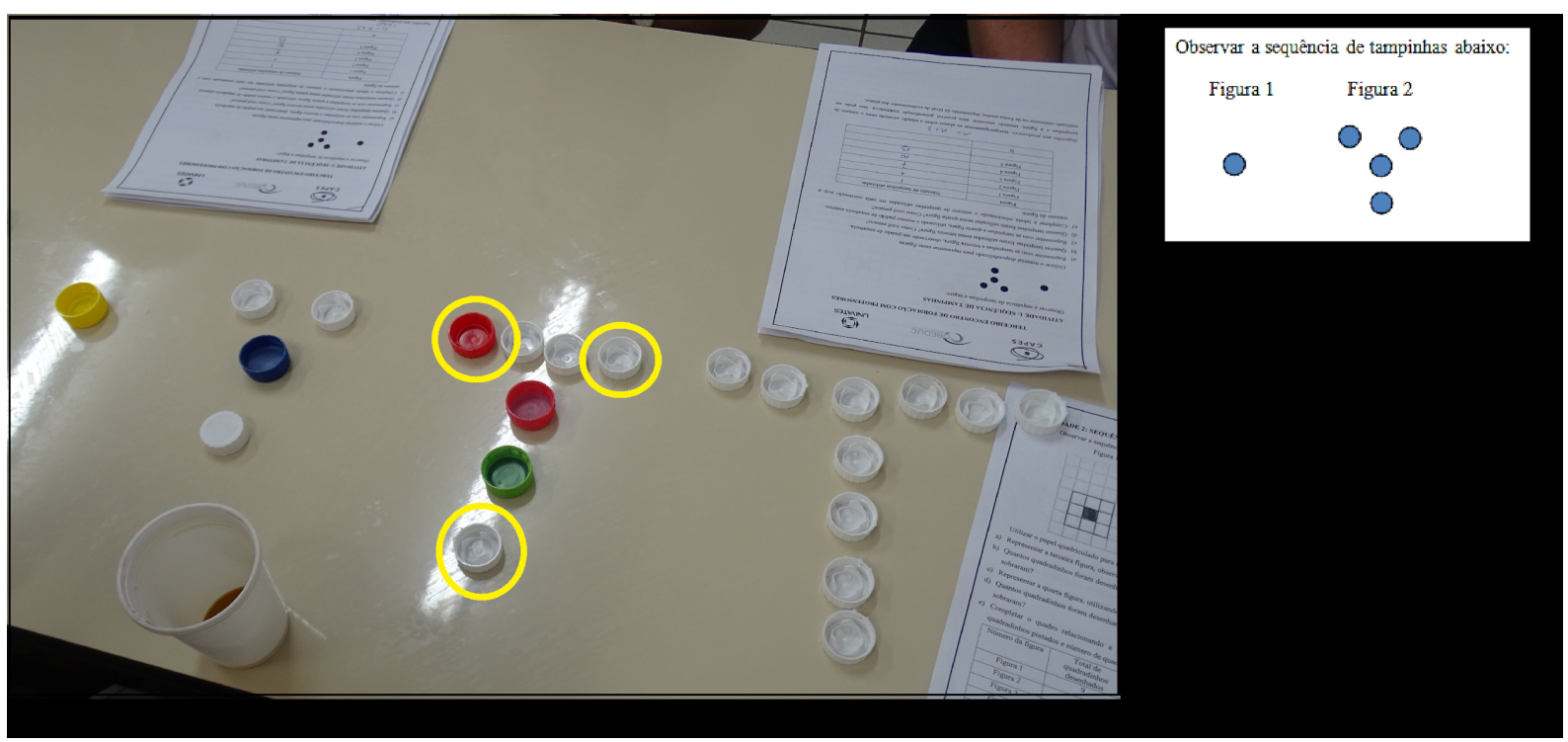

Fonte: Elaborado pelas autoras

Dessa forma, percebe-se que o pensamento encontrado se relaciona com o algébrico, pois se baseou na adição de números. Logo, na tentativa de encontrar uma relação entre as figuras e a equação, de forma que não fosse necessário dispor as tampinhas, as participantes discutiam entre elas, instigadas pela pesquisadora, conforme segue:

PP1 - Figura dois tinha?

D1 - Quatro.

PP1 - As quatro eram como?

D1 - Assim [mostrando a disposição das tampinhas na mesa].

PP1 - E agora?

D1 - Eu só aumentei aqui [referindo-se as três novas tampinhas]

PP1 - E por que tu aumentou ali?

D1 - Não sei, só aumentei três.

PP1 - Mas tu tem que pegar uma relação daqui pra cá [referindo-se à $1^{\mathrm{a}}$ figura para as demais].

D1 - E daí pra cá então, essa é a original [tampinha amarela da imagem $-1^{\text {a }}$ figura].

D2 - $\mathrm{N}$ vezes três, olha gurias [D2 já estava tentando generalizar!].

Ao chegar a um possível padrão enfatizado por D2 [N vezes três], o grupo realizou testes e concluiu que algo estava faltando. Então, suas integrantes voltaram às Figuras e constataram 
que sempre somavam três em relação à anterior. Logo, o número da figura anterior interferia na fórmula. Assim, elas já tinham dois dados: o número três e o da figura anterior. Porém, somente com esses números, suas conjecturas sobre as fórmulas nunca funcionavam para um número infinito. Nesse momento, D3 comentou com suas colegas que "a Figura 1 só tem uma tampinha”. Assim, testaram e conjecturaram conforme resultados no quadro (Figura 5).

Figura 5 - Resultados encontrados pelo Grupo 1

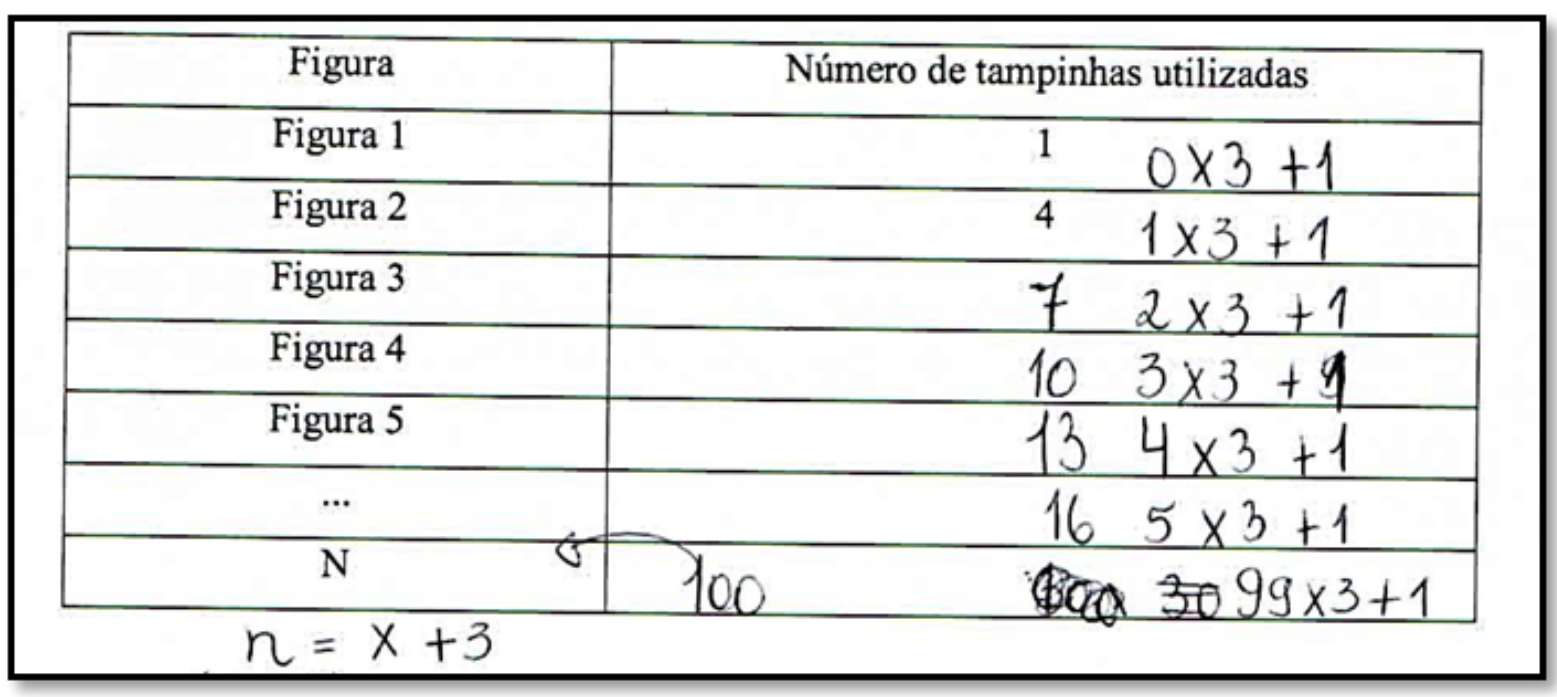

Fonte: Elaborado pelas autoras

Para as docentes, o zero era o número antecedente do um (Figura 1); o três, a quantidade de tampinhas que elas aumentaram em cada figura; o 1, a primeira tampinha (a amarela comentada anteriormente). Assim, concluíram que, para calcular o número de tampinhas que teriam na Figura 3, sem que fosse necessária a construção, deveriam pegar o número antecessor à Figura 3, que é o 2. Então, duas vezes três, mais um, ou seja, o número de tampinhas da Figura 3 é: $2 \times 3+1=7$. Seguindo a conjectura, o Grupo ilustrou como faria o cálculo para a figura de número 100, ou seja: Número de tampinhas $=99$ × $3+1$, em que 99 é o resultado do 100-1; 3, o número de tampinhas a mais em cada figura; e 1, o número de tampinhas da figura original.

Em relação às conjecturas, Ponte et al. (2003, p.23) argumentam que, em situações abertas como essa, cuja questão não está bem definida no início, cabe a quem investiga um papel fundamental na mediação. De outra forma, de uma questão podem emergir diversos pensamentos, ou mesmo resultados diferentes. Dessa maneira, outra conjectura, distinta do Grupo 1, foi a do Grupo 4, que resultou na Figura 6, a seguir. 
Figura 6 - Pensamento adotado pelo Grupo 4

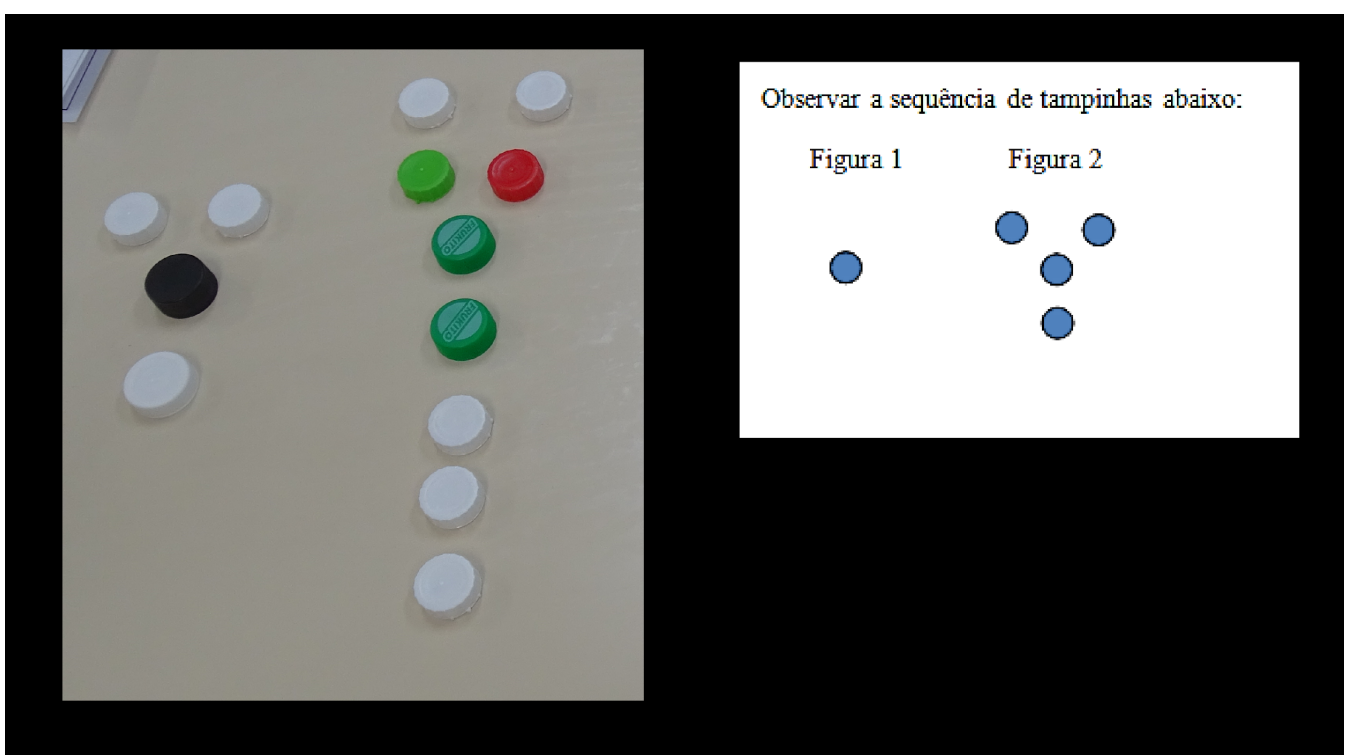

Fonte: Elaborado pelas autoras

Como a Figura 1 e Figura 2 já estavam dispostas para o grupo, suas integrantes partiram da segunda para a terceira figura para encontrar um padrão de generalização. Inicialmente, surgiram alguns diálogos entre elas que foram interessantes para o processo de pensamento sobre qual resolução usariam:

D7 - Figura dois tinha? Se tu pensa assim... um... quatro... aqui tu colocou nove!

D9 - Oito.

D7 - Que sequência tu teria aqui? Como tu pensaria? Isso tem lógica?

D9 - Tem.

PP2 - Um, quatro, nove tem lógica? O que vocês acham?

D7 - Não, tem que ser seis, um n, seria um vezes um, um; dois vezes dois, quatro; três vezes três, seis [aqui a docente se enganou no cálculo].

PP2 - Mas quanto vale o n?

D9 - Acho que faço a fórmula primeiro e depois vejo na figura.

D7 - A próxima seria oito, pode seguir essa sequência também.

PP2 - Um, quatro, nove, como tu ia iniciar? Seria uma lógica?

D2 - A próxima é treze.

D2 - Mas de um até quatro aumentou três; e depois, cinco. Teria que aumentar mais dois. 
Então, D9 insistiu muito em sua conjectura, e as docentes a utilizaram para realizar a próxima figura. De acordo com o pensamento dela, da primeira para a segunda figura, aumentam três; da segunda para a terceira, cinco; ou seja, sempre acrescentava dois ao número de aumentos, pois, três (número que aumentou da $1^{\mathrm{a}}$ para a $2^{\mathrm{a}}$ figura) mais dois gerariam cinco (número que aumentou da $2^{\mathrm{a}}$ para a $3^{\mathrm{a}}$ figura). Ato contínuo, até a $4^{\mathrm{a}}$ figura.

Para entender a disposição das figuras, segue Figura 7:

\section{Figura 7 - Explicação dos autores sobre o pensamento do Grupo 4}
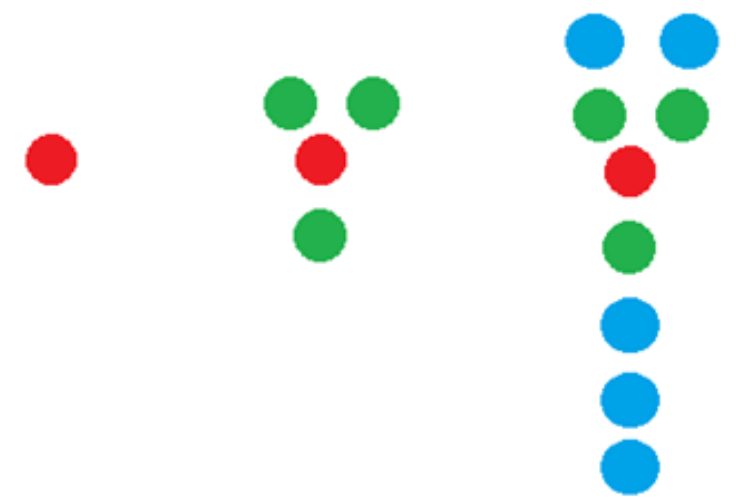

\section{Fig 1 Fig 2
Fonte: Elaborado pelas autoras}

Seguindo o raciocínio do Grupo 4, na Fig 1, está presente apenas uma tampinha, ou seja, Fig 1 = uma tampinha. Na 2, há a tampinha inicial (vermelha) na qual se acrescentam mais três tampinhas; duas acima da inicial e uma abaixo (verdes). Prosseguindo com essa lógica, na 3, permanecem a tampinha vermelha e as verdes, sendo acrescidas mais duas acima e três abaixo (representadas pela cor azul).

Assim, percebe-se uma quantidade ímpar de tampinhas acrescidas abaixo da vermelha (que é a original). Na segunda figura, tem-se uma tampinha (a verde); na terceira, três (as azuis). Para a quarta, seria preciso colocar cinco tampinhas embaixo e assim sucessivamente. Mas ressalta-se que é necessário adicionar sempre mais duas tampinhas na parte superior.

Por fim, para generalizar, D9 comentou com suas colegas que "Quatro, nove está correto, qual é a próxima? O nove é o quê? Três vezes três. O dezesseis é o quatro vezes quatro. É os números ao quadrado, n." Observa-se a troca de ideias e informações entre as participantes, enaltecendo mais uma vez a importância do trabalho em grupo. Segundo Teixeira (1999, p.26):

[...] a criança exercita sua opinião, sua fala, seu silêncio, defendendo seu ponto de vista. O trabalho em grupo, portanto, estimula o desenvolvimento do respeito pelas ideias de todos, a valorização e discussão do raciocínio; dar soluções e apresentar questionamentos, não favorecendo apenas a troca de experiência, de informações, mas criando situações que favorecem o desenvolvimento da sociabilidade, da cooperação e do respeito mútuo entre os alunos, possibilitando aprendizagem significativa.

À medida que as conjecturas eram finalizadas pelos grupos, passou-se às generalizações em grande grupo. Ponte et al. (2003, p.41) afirmam que "sem a discussão final, se corre o risco 
de perder o sentido da investigação". Assim, constatou-se que os Grupos 2, 3 e 5 pensaram de forma semelhante ao primeiro. Apenas o 4 raciocinou de maneira diferente. Os Grupos 6 e 7 não conseguiram generalizar a sequência. O Quadro 1 apresenta um resumo de conjecturas que emergiram durante o processo de desenvolvimento da atividade.

Quadro 1 - Resumo explicativo dos grupos em geral

\begin{tabular}{|c|c|c|}
\hline Grupos & Pensamento & Fórmula \\
\hline $1,2,3,5$ & $\begin{array}{c}\text { Aumentar sempre três em relação à } \\
\text { anterior. }\end{array}$ & ( $\mathrm{N}$ da Figura Anterior x 3) + 1 \\
\hline 4 & $\begin{array}{c}\text { Aumentar sempre números ímpares } \\
\text { embaixo da figura inicial e } \\
\text { acrescentar duas tampinhas a mais } \\
\text { em cada figura na parte superior. }\end{array}$ & $\mathrm{N}^{2}$ \\
\hline 6 e 7 & $\begin{array}{c}\text { Não apresentaram/não concluíram o } \\
\text { seu raciocínio. }\end{array}$ & \\
\hline
\end{tabular}

Fonte: Elaborado pelos autores.

Findos os debates em pequenos, passou-se às generalizações em grande grupo, pois a discussão final sobre a atividade é uma ocasião para promover a reflexão sobre o trabalho realizado. Sendo assim, cabe ao professor proporcionar momentos para que os alunos possam pensar e refletir (FONSECA et al., 1999).

Ainda, sem a discussão final, há o risco de se perderem informações, dados, pensamentos, principalmente por se tratar de uma atividade investigativa e aberta, sem o debate, o compartilhamento de informações, que é o ponto fundamental dessa metodologia. É como fazer a atividade sem sentido, sem propósito, sem objetivo (PONTE et al., 2003).

Ademais, as enunciações dos participantes revelaram momentos de análises sobre suas propostas por meio das quais compreenderam o papel da Investigação Matemática, além da importância de desenvolver o pensamento algébrico antes de introduzir a Álgebra pura. Tal aspecto pode atribuir uma nova qualidade à atividade de ensino dos docentes, mesmo que realizado coletivamente. Por sua vez, as discussões, além um momento de compartilhamento das diferentes conjecturas, promoveram reflexões acerca das práticas que vivenciaram na Escola Básica. Por fim, enfatizaram a relevância da formação continuada e da prática investigativa.

Desse modo, salienta-se que a atividade elencada está em conformidade com os referenciais, visto que os formadores instigaram as participantes a descobrirem novas possibilidades. Nesse tipo de tarefa, o professor passa a ser um orientador e não apenas um transmissor de conteúdo.

\section{CONSIDERAÇÕES FINAIS}

Ao investigar uma nova proposta de ensino, constatam-se muitas dificuldades, principalmente no planejamento, adequação aos níveis de ensino, bem como testes, refinações e avaliação das atividades de cunho exploratório-investigativo. Porém, pode-se inferir que a Investi- 
gação Matemática é uma nova perspectiva do ensino de Matemática nos Anos Iniciais.

O grupo de pesquisadores da Universidade, ao elaborar, problematizar e analisar uma atividade que fizesse o uso da tendência da Investigação Matemática, buscou, principalmente, evidenciar e proporcionar às professoras que participaram da formação continuada novas formas de ensinar Álgebra aos Anos Iniciais, considerando a relação de ensino-aprendizagemavaliação.

No andarilhar da formação, ficou nítido que a atividade envolveu as docentes desde o primeiro momento e proporcionou fases de debates, sobretudo quando pensavam em uma forma de explicar o porquê das estratégias usadas para a resolução da atividade. No caso do desenvolvimento desta tarefa investigativa, emergiram duas diferentes conjecturas para a situação. Na primeira, as participantes sempre acresciam três em relação à figura anterior, seguindo um padrão. Elas colocavam duas tampinhas em cima, uma em cada lado e uma embaixo da figura anterior, que já estava formada, de maneira que totalizassem três. A expressão algébrica que surgiu foi tampinhas $=\left[\mathrm{n}^{\circ}\right.$ da figura multiplicado por 3$]+1$. No outro grupo, o pensamento nasceu da ideia de aumentar números ímpares na parte inferior da figura original e duas tampas na superior, ou seja, tampinhas $=\mathrm{n}^{2}$.

A atividade desenvolvida também permitiu observar que o professor (e também o aluno) não aprende isoladamente, mas sim interagindo com outros, pois, segundo Dayan (2007, p.17), "além da técnica da discussão, o pensar juntos passa a constituir um objetivo pedagógico". Assim, a argumentação possibilita que o grupo pense, erre e repense sua estratégia. Em síntese, cabe ao docente mediar esse processo de aprendizagem, buscando, com seu aprendiz, distintas maneiras para explicar o mesmo problema.

Como continuidade, o grupo de pesquisa busca inovar pesquisando novas tarefas para fomentar o estudo de Álgebra desde os Anos Iniciais, bem como a sua implementação nas escolas. Ademais, discute meios de avaliação, já que essa tendência permite respostas múltiplas. Dessa forma, as perguntas que surgem são: Como avaliar atividades exploratório-investigativas? Avaliação individual, mas as atividades investigativas são discutidas e resolvidas em grupo? Em grupo, mas as contribuições são individuais? Autoavaliação? Essas são algumas perspectivas com as quais a equipe se depara no prosseguimento desta pesquisa. 


\section{REFERÊNCIAS}

ALMEIDA, J. R. Modelo de níveis de desenvolvimento de pensamento algébrico: o caso dos problemas de partilha. 2016. Tese (Doutorado) - Tese de doutorado em desenvolvimento em Ensino das Ciências. UFRPE.

BLANTON, Maria L; KAPUT, James J. Characterizing a classroom practice that promotes algebraic reasoning. Journal for research in mathematics education, JSTOR, p. 412-446, 2005.

BRASIL, Ministério da Educação. Base nacional comum curricular. BNCC 2a versão. Brasília, DF, 2017.

BÚRIGO, EZ et al. A Matemática na Escola: Novos Conteúdos, Novas Abordagens, Série Educação a Distância. Porto Alegre: Editora da UFRGS, 2012. Disponível em: <http://www. ufrgs.br/espmat/livros/livro1-matematica_escola.pdf>.

DAYAN, Silvia Parrat. A discussão como ferramenta para o processo de socialização e para a construção do pensamento. Educ. rev, n. 45, p. 13-23, 2007.

DEMO, P. Educar pela pesquisa. Campinas: Autores Associados, 2007.

FONSECA, Helena; BRUNHEIRA, Lina; PONTE, JP da. As actividades de investigação, o professor e a aula de matemática. Actas do ProfMat, v. 99, p. 91-101, 1999.

FREITAS, Wesley RS; JABBOUR, Charbel JC. Utilizando estudo de caso (s) como estratégia de pesquisa qualitativa: boas práticas e sugestões. Revista Estudo \& Debate, v. 18, n. 2, 2011.

GHELLI K. G. M; SANTOS, A. O; OLIVEIRA G. S. Investigações matemáticas: fundamentos teóricos para aprendizagem matemática nas séries iniciais do ensino fundamental. In: ENCONTRO DE PESQUISA EM EDUCAÇÃO, 7., 2015, Uberaba. Anais... Uberaba: UNIUBE, 2015.

GIBBS, Graham. Análise de dados qualitativos. Porto Alegre: Artmed, 2009.

GROENWALD, C. L. O. Pensamento aritmético e pensamento algébrico no ensino fundamental: fundamentos teóricos para aprendizagem matemática nas séries iniciais do ensino fundamental. In: ENCONTRO NACIONAL PIDIB MATEMÁTICA, 4., 2014, Santa Maria. Anais... Santa Maria: UFSM, 2014.

KIERAN, Carolyn. Algebraic thinking in the early grades: What is it. The Mathematics Educator, Athens, GA, v. 8, n. 1, p. 139-151, 2004.

PONTE, João Pedro da; BROCARDO, Joana; OLIVEIRA, Hélia. Investigações matemáticas na sala de aula. Belo Horizonte: Autêntica Editora, 2003. v. 7.

SANTOS, Cleibianne Rodrigues dos; SIQUEIRA, Daniela de Andrade. Materiais manipuláveis: Uma reflexão de sua utilização na ensinagem de matemática. Encontro Goiano de Educação Matemática, v. 6, n. 6, p. 608-617, 2017.

SARMENTO, Alan Kardec Carvalho. A utilização dos materiais manipulativos nas aulas de matemática. In: ENCONTRO DE PESQUISA EM EDUCAÇÃO, 6, 2010, Teresina. Anais... Piauí: UFPI, 2010. Disponível em: <http://leg.ufpi.br/subsiteFiles/ppged/arquivos/files/VI.encontro. 2010/GT_02_18_2010.pdf>. 
SCHEIN, Zenar Pedro; COELHO, Suzana Maria. O papel do questionamento: intervenções do professor e do aluno na construção do conhecimento. Caderno Brasileiro de Ensino de Física, v. 23, n. 1, p. $72-98,2006$.

STEELE, Diana F. Vozes entusiastas de jovens matemáticos. Educação e Matemática, Lisboa, v. 62, p. 39-42, 2001.

TEIXEIRA, Cícera F. Compreensão, criação e resolução de problemas de estrutura multiplicativa: uma sequência didática com problemas “abertos". 1999. Monografia (Especialização em ensino de pré a $4^{\mathrm{a}}$ série) — Universidade Federal do Pernambuco, Recife.

VASCONCELLOS, Celso dos Santos. Construção do conhecimento em sala de aula. São Paulo: Lebertad, 1999.

VEIGA, Ilma Passos Alencastro. O seminário como técnica de ensino socializado. In: VEIGA, ILMA PASSOS ALENCASTRO (ORG). Técnicas de ensino: por que não? Campinas: Papirus, 1991. p. 103-113. 